\title{
Efeito da irrigação sobre o rendimento produtivo da alface americana, em cultivo protegido ${ }^{1}$
}

\author{
Joaquim A. de Lima Júnior ${ }^{2}$, G eraldo M. Pereira ${ }^{3}$, Luciano 0. G eisenhoff ${ }^{2}$, G ustavo G. Costa ${ }^{4}$, Renato C. Vilas Boas ${ }^{2}$ \& Jony E. Yuri ${ }^{5}$
}

\section{RESU MO}

Visando reduzir as dificuldades do produtor no cultivo da alface americana, especificamente quanto à falta de informações técnicas sobre a quantidade de água a ser aplicada, objetivou-se estudar 0 efeito de diferentes lâminas de água referentes às características produtivas da alface americana. 0 experimento foi realizado na U niversidade Federal de Lavras, no período de março a maio de 2008, em casa de vegetação. 0 delineamento experimental foi em blocos casualizados, com cinco tratamentos e quatro repetições. $0 \mathrm{~s}$ tratamentos foram constituídos de cinco fatores de evaporação, correspondentes a 0,30, 0,60, 0,90, 1,20 e 1,50 EVm (lâmina evaporada), baseado na lâmina evaporada de um minitanque. $0 \mathrm{~s}$ resultados permitiram concluir que o número de folhas internas e a circunferência da cabeça comercial tiveram resposta quadrática aos tratamentos, com valores máximos alcançados entre o intervalo de 0,95 a 1,10 de reposição da lâmina evaporada; a máxima produtividade comercial, $35.308 \mathrm{~kg} \mathrm{ha}^{-1}$, foi estimada com a aplicação da lâmina de $204,3 \mathrm{~mm}$, correspondente ao fator de reposição de 1,01; a maior eficiência no uso da água $\left(563,07 \mathrm{~kg} \mathrm{ha}^{-1} \mathrm{~mm}^{-1}\right)$ ocorreu com a aplicação da lâmina de irrigação, de $74,53 \mathrm{~mm}(0,30)$.

Palavras-chave: Lactuta sativa L., lâmina de irrigação, ambiente protegido

\section{Effect of irrigation on the crisphead lettuce yield, in protected environment}

\begin{abstract}
With the aim of minimizing the difficulties faced by producers of crisphead lettuce, specifically those related to the lack of technical information about the quantity of water to be applied, a study was conducted in order to determine the effect of various water depths on the crisphead lettuce yielding characteristics. The experiment was carried out at the Universidade Federal de Lavras, from March to May 2008 in greenhouse. A randomized block design with five treatments and four repetitions was used. The treatments, consisting of five levels of evaporation: 0.30, 0.60, 0.90, 1.20 and $1.50 \mathrm{EVm}$ (evaporate depth), based on depth evaporated in a reduced pan. The results show ed that the number of internal leaves and commercial head circumference present a quadratic response to the treatments, where the maximum values were reached at evaporated depth intervals of 0.95 to 1.10; the maximum commercial productivity, $35,308 \mathrm{~kg} \mathrm{ha}^{-1}$, was estimated by applying a $204.3 \mathrm{~mm}$ depth, which corresponded to a water reposition factor of 1.01; the highest water use efficiency (563.07 kg ha-1 $\mathrm{mm}^{-1}$ ) was attained when an irrigation depth of $74.53 \mathrm{~mm}(0.30)$ was used.
\end{abstract}

Key words: Lactuta sativa L., irrigation depths, protected environment

\footnotetext{
1 Parte da Dissertação de Mestrado em Engenharia de Água e Solo, apresentada pelo primeiro autor à Universidade Federal de Lavras (UFLA)

2 Doutorando, DEG/UFLA, CP 3037, CEP 37200-000, Lavras, MG. Fone: (35) 3829-1389, e-mail: alveslima@posgrad.ufla.br

3 DEG/U FLA, Bolsista do CN Pq, e-mail: geraldop@ufla.br

${ }^{4}$ Mestrando DEG/UFLA, e-mail: gustavocapitolio@yahoo.com.br

5 DA/U N IN COR Universidade Vale do Rio Verde, Av. Castelo Branco, 82, Centro, CEP 37410-000, Três Corações, M G. Fone: (35) 3239-1000, e-mail: jonyyuri@uol.com.br
} 


\section{INTRODUÇÃO}

A alface (Lactuca sativa L.) é a principal hortaliça folhosa comercializada e consumida pela população brasileira pela facilidade de aquisição e por ser produzida o ano inteiro (Oliveira et al., 2004). Ressalta-se que o volume de alface comercializado na CEAGESP-SP em 2007, foi de 28.389 toneladas, colocando-a, neste ano, na liderança nacional em comercialização e consumo (Agrianual, 2008).

Dentre os tipos existentes de alface, merece destaque o plantio da alface tipo americana por atender à demanda principalmente às redes "fast foods" da região. Atualmente, no sul de Minas Gerais um grupo de produtores dessa hortaliça tem produzido cerca de 1.000 toneladas brutas por mês, apenas para abastecer uma grande rede de lojas (Yuri et al., 2004). A alface americana se diferencia dos demais tipos por apresentar folhas externas de coloração verde-escuro, folhas internas de coloração amarela ou branca, imbricadas semelhantes ao repolho e crocantes, além de maior vida pós-colheita, possibilitando o transporte a longas distâncias (Yuri et al., 2002).

O cultivo em ambiente protegido é uma ferramenta muito útil para a aquisição de alta produção e de produtos de excelente qualidade, por manter um clima mais propício ao desenvolvimento da cultura ao longo do ano (Segovia et al., 1997). Além disso, o cultivo protegido depende menos das condições climáticas, amenizando possíveis infestações de pragas e doenças, que passam a aumentar o custo de produção da cultura.

A alface é uma cultura exigente em água, sendo o manejo adequado da irrigação importante não apenas por suprir as necessidades hídricas das plantas mas, também, por minimizar problemas com doenças e lixiviação de nutrientes, bem como gastos desnecessários com água e energia (Koetz et al., 2006).

Segundo Volpe \& Churata-Masca (1988) existem vários métodos para se efetuar o manejo da água de irrigação e, dentre eles, se destaca o do tanque Classe $\mathrm{A}$, devido à sua facilidade de operação, a custo relativamente baixo e, sobretudo, em virtude da possibilidade de instalação próxima à cultura a ser irrigada; no entanto, visando diminuir o custo do tanque Classe A em razão do espaço reduzido no interior das casas de vegetação, tem-se adotado tanques de evaporação com dimensões reduzidas (minitanque), como alternativa para a estimativa da evapotranspiração.

Andrade Júnior \& Klar (1997) estudando o efeito de quatro níveis de irrigação com base na evaporação do tanque Classe A (ECA) $(25,50,75$ e 100\%), utilizando irrigação por gotejamento na cultura da alface tipo americana, obtiveram valor máximo para produtividade total de $90 \mathrm{t} \mathrm{ha}^{-1}$, com o nível de irrigação correspondente a $75 \%$ da ECA.

Silva et al. (2008) obtiveram efeito quadrático para circunferência da cabeça comercial da alface americana, cujo valor máximo de circunferência foi de $44,94 \mathrm{~cm}$, com uma lâmina total de água de 170,81 mm, correspondente a 91,66\% da lâmina de reposição.

Devido à importância do cultivo em ambiente protegido para a cultura da alface no Brasil, torna-se de grande rele- vância o desenvolvimento de pesquisas que subsidiem o aproveitamento do potencial dessa tecnologia nas diferentes regiões climáticas do País, notadamente aqueles necessários ao manejo adequado da irrigação (Vilas Boas et al., 2007).

Objetivou-se, com o presente trabalho, avaliar o efeito de lâminas de irrigação sobre os rendimentos produtivos da alface americana, em ambiente protegido, na região de Lavras, MG.

\section{MATERIAL E MÉTODOS}

O experimento foi desenvolvido em casa de vegetação situada na área experimental do Departamento de Engenharia da Universidade Federal de Lavras (UFLA), no período compreendido entre março e maio de 2008. A UFLA se situa em Lavras, sul de Minas Gerais, e está em uma altitude média de $918,8 \mathrm{~m}$, latitude $21^{\circ} 14^{\prime} \mathrm{S}$ e longitude $45^{\circ} 00^{\prime}$ W Gr.

De acordo com a classificação de Köppen (Dantas et al., 2007), a região apresenta clima Cwa, ou seja, clima temperado chuvoso (mesotérmico), com inverno seco e verão chuvoso, temperatura média do mês mais frio inferior a $18^{\circ} \mathrm{C}$ e superior a $3{ }^{\circ} \mathrm{C}$; o verão apresenta temperatura média do mês mais quente superior a $22{ }^{\circ} \mathrm{C}$.

A casa de vegetação foi construída com estrutura metálica do tipo teto em arco, apresentando $2,5 \mathrm{~m}$ de pé-direito, 4,0 m de altura no ponto mais alto, 13,0 m de comprimento e 7,0 m de largura, coberta com filme de polietileno de baixa densidade transparente, aditivado anti-UV com espessura de $150 \mu$ e as laterais fechadas com tela antiafídeo. O solo da área experimental foi originalmente classificado como Latossolo Vermelho Distroférrico, segundo a EMBRAPA (1999).

Empregou-se o delineamento em blocos casualizados (DBC), com cinco tratamentos e quatro repetições, perfazendo o total de 20 parcelas. Os tratamentos se constituíram de cinco lâminas de água, com base na evaporação do minitanque, sendo: W1, W2, W3, W4 e W5 referentes às lâminas de irrigação de 30,60, 90, 120 e $150 \%$ da evaporação do minitanque, respectivamente.

O minitanque tem forma circular, construído em chapa galvanizada com $60,5 \mathrm{~cm}$ de diâmetro $(50 \%$ do diâmetro do tanque Classe A), $25,4 \mathrm{~cm}$ de profundidade apoiado sobre estrado de madeira com altura de $15 \mathrm{~cm}$ acima do solo. $\mathrm{O}$ minitanque foi instalado no centro de uma das casas de vegetação, conforme Figura 1.

As parcelas experimentais apresentaram as dimensões de 1,20 m de largura e 2,40 m de comprimento, totalizando uma área de $2,88 \mathrm{~m}^{2}$. Quatro linhas de plantas espaçadas $0,30 \mathrm{~m}$ entre linhas e $0,30 \mathrm{~m}$ entre plantas foram utilizadas, perfazendo o total de 32 plantas por parcela, considerando-se úteis as plantas das linhas centrais e se descartando nessas linhas duas plantas no início e duas no final de cada parcela (parcela útil com $0,72 \mathrm{~m}^{2}$ e 8 plantas).

Utilizou-se de sistema de irrigação por gotejamento, sendo as linhas laterais compostas de emissores com vazão de $1,76 \mathrm{~L} \mathrm{~h}^{-1}$, diâmetro nominal (DN) de $16 \mathrm{~mm}$ distanciados 


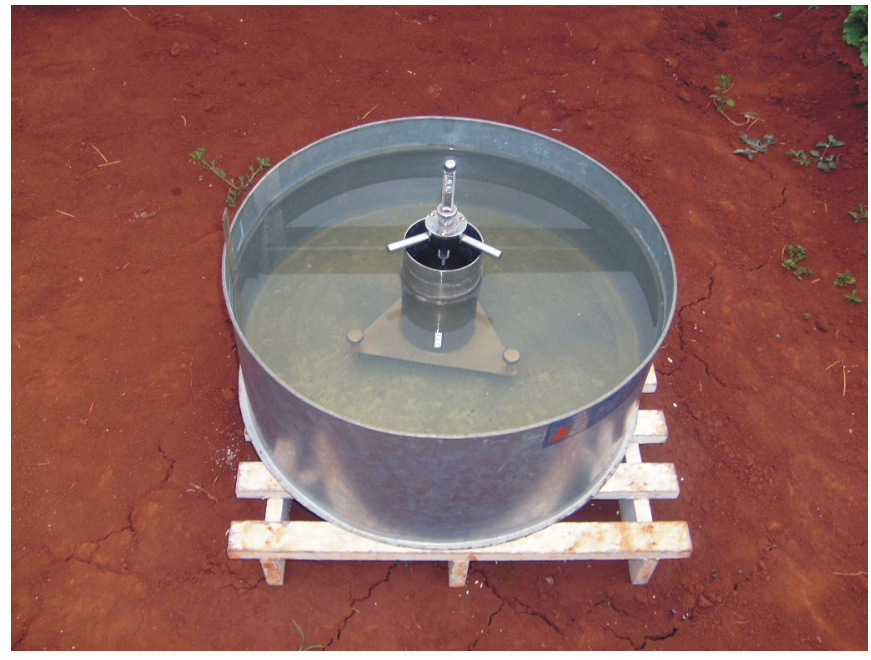

Figura 1. M initanque evaporimétrico utilizado no experimento

entre si a $0,30 \mathrm{~m}$, ficando posicionados na parcela, de forma a atender às duas fileiras de plantas, trabalhando com pressão de serviço em torno de 18 mca, que era regulada por meio de uma válvula reguladora de pressão inserida no cabeçal de controle.

As linhas laterais foram conectadas às linhas de derivação de polietileno (PEBD DN $16 \mathrm{~mm}$ ); estas, por sua vez, foram conectadas às linhas principais (PVC DN $35 \mathrm{~mm}$; PN 40) que tinham, no seu início, válvulas de comando elétrico (solenóides) localizadas na saída do cabeçal de controle. Utilizou-se também uma válvula para cada tratamento; tais válvulas eram acionadas por meio de um controlador lógico programável (Total Control 12 Stations), previamente programado em cada irrigação, para funcionar o tempo necessário visando repor a lâmina de cada tratamento.

Calculou-se a lâmina de água aplicada com frequência de dois dias, considerando-se a porcentagem da evaporação (K) medida no período previsto entre duas irrigações (2 dias), de acordo com cada tratamento e a eficiência de aplicação de água do sistema de irrigação, conforme a Eq. 1.

$$
\mathrm{LI}=\frac{\mathrm{EVm} \cdot \mathrm{K}}{\mathrm{Ei}}
$$

em que:

LI - lâmina de irrigação a ser aplicada em cada tratamento, mm

EVm - evaporação do minitanque medida no período, $\mathrm{mm}$

Ei - eficiência de aplicação de água do sistema, 0,90

$\mathrm{K}$ - fração da evaporação de cada tratamento

Obtiveram-se as diferentes lâminas de irrigação para cada tratamento mediante diferentes tempos de funcionamento das linhas de gotejadores; este tempo foi obtido a partir da vazão média dos gotejadores, do espaçamento entre plantas e entre linhas de plantio, conforme a Eq. 2.

$$
\mathrm{Ti}=\frac{\text { LI.Sp.Slp }}{\text { e.q }}
$$

em que:

Ti - tempo de irrigação para cada tratamento, $\mathrm{h}$

LI - lâmina de irrigação a ser aplicada no tratamento, $\mathrm{mm}$

Sp - espaçamento entre plantas, 0,30 m

Slp - espaçamento entre linhas de plantas, 0,30 m

e - número de emissores por planta, 0,5

$\mathrm{q}$ - vazão média do gotejador, $1,76 \mathrm{~L} \mathrm{~h}^{-1}$

A cultivar utilizada foi a Raider-Plus, do tipo americana, por ser de grande aceitabilidade pelos produtores de Lavras e região e em razão de apresentar elevada demanda pelas empresas de "fast foods" e consumidores. A adubação básica foi realizada vinte e um dias antes do transplantio, com base na análise química do solo e conforme as recomendações de Gomes et al. (1999).

Toda a adubação de cobertura foi realizada via fertirrigação seguindo-se, também, as recomendações de Gomes et al. (1999); os fertilizantes utilizados foram o nitrato de potássio, o nitrato de cálcio e o sulfato de magnésio. O total de nutrientes fornecidos para a cultura, ou seja, a soma da adubação básica com a de cobertura, totalizou a quantidade em $\mathrm{kg} \mathrm{ha}^{-1}$ de: 115,34 de N; 79,20 de P; 173,76 de K; 115,46 de $\mathrm{Ca} ; 12,20$ de $\mathrm{Mg}$ e 15,60 de S.

As mudas foram doadas por um produtor do município de Três Pontas, MG, as quais foram semeadas em bandejas de isopor de 288 células preenchidas com o substrato comercial Plantmax ${ }^{\circledR}$ HT, específico para o cultivo da alface. Após 30 dias da semeadura, ocasião em que as mudas já se encontravam com quatro folhas definitivas, efetuou-se o transplantio para os canteiros.

Do transplantio, ocorrido em nove de abril de 2008, até o início da diferenciação dos tratamentos (14/04) foram realizadas, por quatro dias, irrigações, nos cinco tratamentos, totalizando uma lâmina de $24 \mathrm{~mm}$. Este procedimento teve como objetivo proporcionar um melhor "pegamento" e a uniformização no desenvolvimento inicial das mudas.

A colheita foi efetivada no dia 30 de maio de 2008, quando as plantas atingiram seu máximo desenvolvimento vegetativo; isto ocorre quando as cabeças da alface americana se encontram bem enfolhadas e compactas. As avaliações foram realizadas imediatamente após a colheita das parcelas úteis.

Para a análise estatística das características físicas e produtivas da alface americana, considerou-se a soma das irrigações feitas antes e após o início da diferenciação dos tratamentos, denominada lâmina total.

Para obtenção das características avaliadas, as plantas foram pesadas para estimativa da produtividade total, considerando-se 79.226 plantas por hectare. Para obter o peso total da cabeça comercial as plantas foram desfolhadas até atingir o ponto ideal de comercialização. Para a estimativa da produção comercial, as cabeças de alface foram pesadas e os valores encontrados convertidos para $\mathrm{kg} \mathrm{ha}^{-1}$, depois de pesada, procedeu-se à medida de sua circunferência com o auxilio de uma fita métrica. As folhas internas da cabeça comercial foram retiradas procedendo-se à sua contagem e pesagem e a eficiência no uso da água foi determinada pela relação entre os valores da produtividade total $\left(\mathrm{kg} \mathrm{ha}^{-1}\right)$ e as respectivas quantidades de água consumidas em cada trata- 
mento durante o cultivo. Os dados amostrados foram submetidos a análise de variância com a realização do teste $\mathrm{F}$ e análise de regressão a 5 e $1 \%$ de probabilidade, utilizandose o programa Sisvar 4.0.

\section{RESULTADOS E DISCUSSÃO}

No período de condução do experimento as médias de temperatura e a umidade relativa do ar no interior da casa de vegetação foram de $20,3{ }^{\circ} \mathrm{C}$ e $67,2 \%$, respectivamente. $\mathrm{O}$ referido valor de temperatura se encontra dentro da faixa ótima recomendada por Santana et al. (2009), que relatam a faixa de 15 e $20^{\circ} \mathrm{C}$ como adequada ao bom desenvolvimento da alface, entretanto, esses autores também afirmam que, quando cultivada em regiões de temperatura e luminosidade elevadas, esta hortaliça deixa de desenvolver todo o seu potencial genético.

A evaporação do minitanque coletada diariamente entre as 8 e $9 \mathrm{~h}$ durante o período de condução do experimento e aplicação dos tratamentos, está apresentada na Figura 2. A evaporação máxima diária foi de $5,02 \mathrm{~mm}$, a mínima de $1,09 \mathrm{~mm}$ e a média resultou em $3,10 \mathrm{~mm}$.

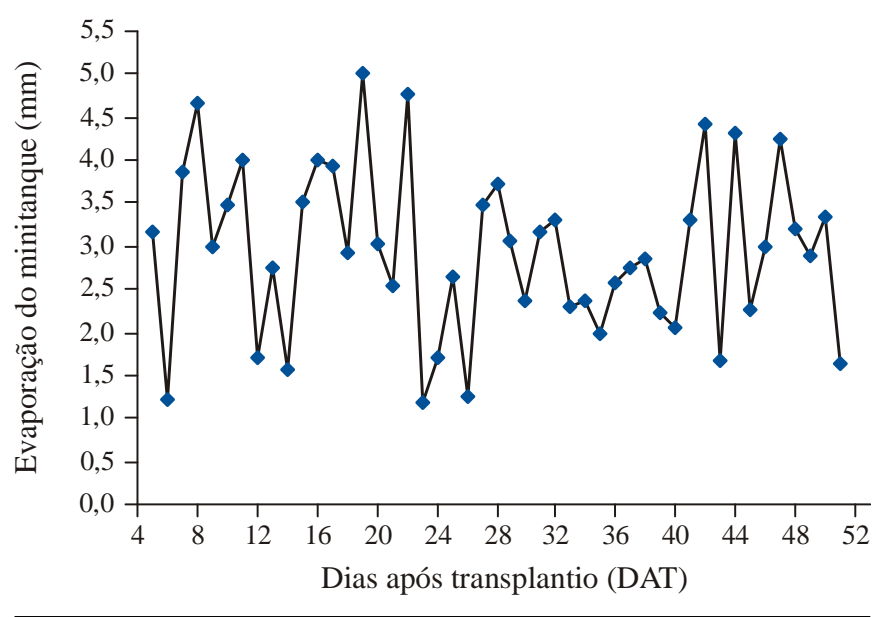

Figura 2. Evaporação diária do minitanque ocorrida no interior da casa de vegetação

Os valores acumulados das lâminas aplicadas após a diferenciação dos tratamentos se encontram na Figura 3, na qual se observa, na fase inicial do experimento, uma pequena diferenciação entre as lâminas de irrigação; esta diferença se foi acentuando durante o experimento e, no final do ciclo da cultura, aos 52 DAT, as lâminas de irrigação aplicadas após a diferenciação foram de 50,5, 104,6, 157,0, 209,4 e 261,7 mm nos tratamentos W1, W2, W3, W4 e W5, respectivamente. A lâmina aplicada no tratamento W5 foi aproximadamente cinco vezes superior à lâmina aplicada no tratamento W1, evidenciando ter ocorrido uma ampla variação no teor de água no solo, para o desenvolvimento da alface.

As produtividades total e comercial foram significativamente afetadas pelo efeito das lâminas de água aplicadas ao solo, a 5 e $1 \%$ de probabilidade, pelo teste F (Tabela 1), respectivamente.

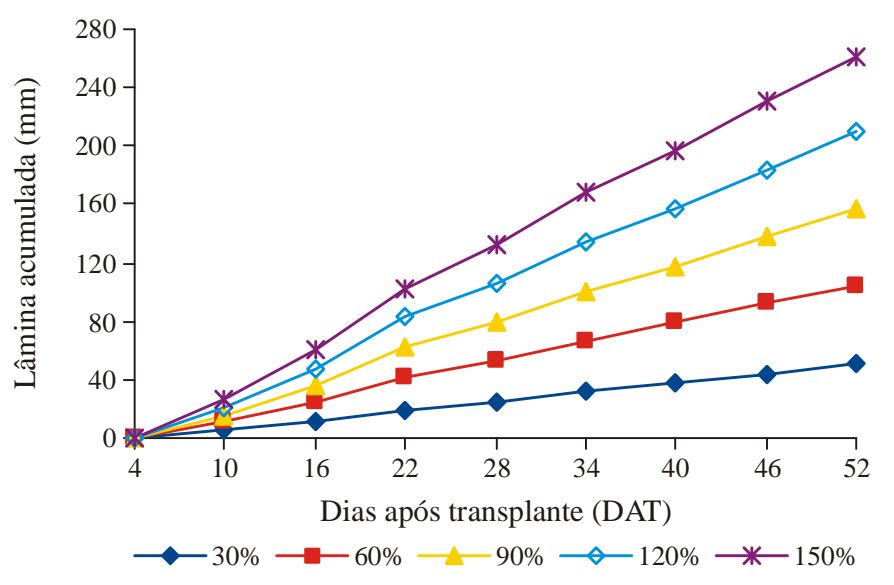

Figura 3. Lâmina de irrigação acumulada aplicada nos tratamentos W 1 , W2, W3, W 4 e W5, ao longo do ciclo da cultura

Tabela 1. Resumo das análises de variância e de regressão quanto à produtividade total (PT) e a produtividade da cabeça comercial (PCC), em função de diferentes lâminas de irrigação

\begin{tabular}{lccc}
\hline \multirow{2}{*}{ Fonte de Variação } & G. L. & \multicolumn{2}{c}{ Q. M. } \\
\cline { 3 - 4 } Lâmina & 4 & P13149255,30* & $163470154,60^{* *}$ \\
Bloco & 3 & $23664591,60^{\text {ns }}$ & $23168628,20^{\text {ns }}$ \\
Resíduo & 12 & 66829804,20 & 21445637,30 \\
Média (kg ha-1) & - & 57586,40 & 29763,55 \\
C.V. (\%) & - & 14,20 & 15,56 \\
Linear & 1 & $422880600,80^{*}$ & $209439328,40 * *$ \\
Quadrática & 1 & $757393674,10^{* *}$ & $362367828,50 * *$ \\
Desvios & 2 & $36161373,20^{\text {ns }}$ & $41036730,80^{\text {ns }}$ \\
\hline ns - não significativo pelo teste F & \multicolumn{3}{|}{} \\
${ }^{*}$ e $^{* *}-$ significativos a 5 e 1\% de probabilidade pelo teste F, respectivamente
\end{tabular}

No caso da produtividade total e comercial, as variações ocorridas podem ser explicadas por uma regressão linear ou quadrática, tendo a segunda opção apresentado maior coeficiente de determinação $\left(\mathrm{R}^{2}\right)$ para as duas variáveis, conforme a Figura 4. A resposta quadrática indica um acréscimo na produtividade total e comercial da cabeça, na medida em que se aumentaram as lâminas de irrigação. O ponto máximo para a produtividade total foi estimado com uma lâmina de 203,9 mm, equivalente a uma produtividade para esta variável, de $65.578 \mathrm{~kg} \mathrm{ha}^{-1}$, já para a produtividade da cabeça comercial o ponto máximo foi atingido com a aplicação da lâmina de irrigação de 204,3 mm, resultando em uma produtividade para este parâmetro, de $35.308 \mathrm{~kg} \mathrm{ha}^{-1}$.

Os resultados encontrados neste trabalho estão abaixo dos indicados por Santos \& Pereira (2004) que obtiveram, para produtividade total e comercial da alface americana, valores máximos de 71.180 e $49.380 \mathrm{~kg} \mathrm{ha}^{-1}$, respectivamente, irrigando quando a tensão de água no solo, a $0,15 \mathrm{~m}$ de profundidade, estava em torno de $15 \mathrm{kPa}$. A lâmina total de irrigação fornecida foi de $152,7 \mathrm{~mm}$.

Vilas Boas et al. (2007) encontraram valores máximos de produtividade total e comercial em experimento com alface crespa, irrigada por gotejamento, de 36.484 e $33.225 \mathrm{~kg} \mathrm{ha}^{-1}$, com aplicação das lâminas 249,1 e 244,9 mm para produtividade total e comercial, respectivamente. 


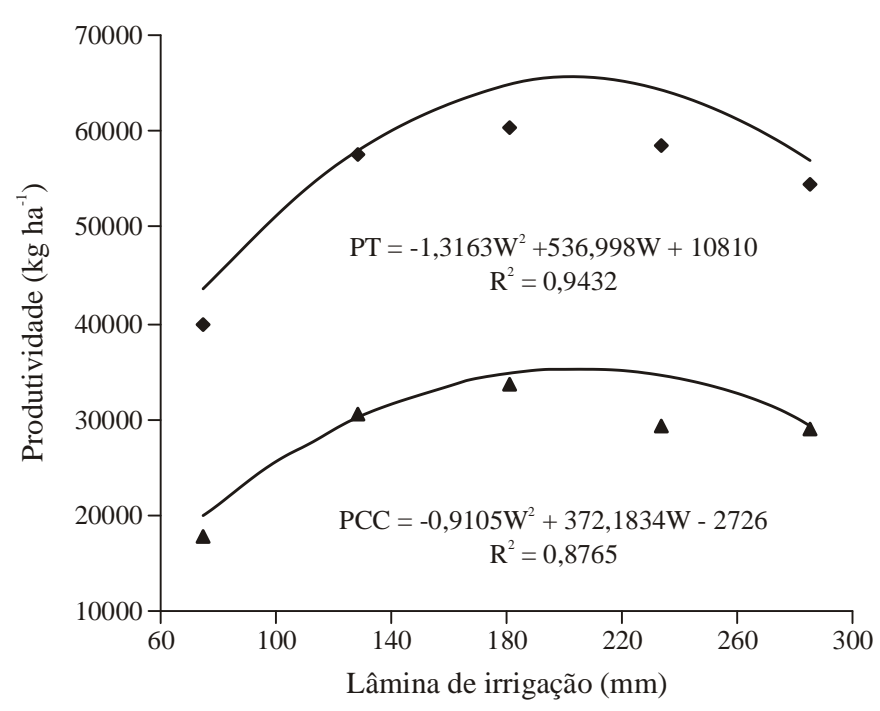

Figura 4. Valores médios, observados e estimados, da produtividade total (PT) e da produtividade da cabeça comercial (PCC) de alface americana, em função das lâminas de irrigação

Andrade Júnior \& Klar (1997) encontraram valor máximo de $90.000 \mathrm{~kg} \mathrm{ha}^{-1}$, com o nível de irrigação correspondente a $75 \%$ da ECA; este resultado foi superior ao deste trabalho, podendo ser justificado pela cultivar utilizada pelos autores e também pela variação ambiental da região em que o experimento foi realizado.

Nesta mesma linha de pesquisa, Silva et al. (2008) testando diferentes lâminas de irrigação na cultivar Raider-Plus, do tipo americana, obtiveram resposta semelhante, alcançando produtividade comercial de $27.004,49 \mathrm{~kg} \mathrm{ha}^{-1}$, aplicando uma lâmina de água em torno de 208,03 mm.

Pelúzio (1992) obteve resultado diferente do obtido neste trabalho quando testou o nível máximo de 1,4 da ECA, que não proporcionou a ocorrência do efeito negativo por excesso de água devido, provavelmente, às características físicas do solo que, por ser de textura arenosa, permitiu a perda de água por percolação profunda além de reter pouca água disponível.

Observa-se, pela curva, redução na PT e na PCC com a aplicação da lâmina de $285,63 \mathrm{~mm}$, correspondente ao tratamento de 1,5 da lâmina evaporada (W5), fato este devido, possivelmente, ao excesso de umidade em torno do sistema radicular da planta, dificultando o arejamento e provocando, assim, anomalias de origem fisiológica e a lixiviação de nutrientes; desta forma, onera a cultura sem nenhum beneficio, representando também desperdício de água e energia, dois sérios problemas no mundo atual (Filgueira, 2003).

A circunferência da cabeça comercial e o número de folhas internas apresentaram resposta quadrática em relação às lâminas de irrigação (Tabela 2).

$\mathrm{O}$ efeito quadrático da aplicação de água no solo (Figuras $5 \mathrm{~A}$ e B) apresentou um acréscimo na circunferência e no número de folhas internas da alface, sempre que se aumentou a quantidade de água aplicada, até as lâminas de 197,4 e 197,2 mm, respectivamente, alcançando valores máximos para a CCC de $57,37 \mathrm{~cm}$ e para o NFI de 15 folhas, que equivalem a $98 \%$ da lâmina de reposição; assim, a umidade
Tabela 2. Resumo das análises de variância e de regressão quanto à circunferência da cabeça comercial (CCC) e o número de folhas internas da cabeça comercial (NFI), em função de diferentes lâminas de irrigação

\begin{tabular}{lccc}
\hline \multirow{2}{*}{ Fonte de Variação } & G. L. & \multicolumn{2}{c}{ Q. M. } \\
\cline { 3 - 4 } Lâmina & 4 & $65,59^{*}$ & NFI \\
Bloco & 3 & $31,94^{\text {ns }}$ & $9,52^{*}$ \\
Resíduo & 12 & 17,27 & $1,02^{\text {ns }}$ \\
Média (cm, ud.) & - & 51,83 & 2,87 \\
C.V. (\%) & - & 8,02 & 13,56 \\
Linear & 1 & $12,96^{\text {ns }}$ & 12,50 \\
Quadrática & 1 & $237,37^{* *}$ & $4,95^{\text {ns }}$ \\
Desvios & 2 & $6,01^{\text {ns }}$ & $28,46^{*}$ \\
\hline
\end{tabular}

ns - não significativo pelo teste $F$

${ }^{*} \mathrm{e}^{* *}$ - significativos a 5 e $1 \%$ de probabilidade pelo teste $F$, respectivamente

no solo favoreceu, de forma direta, o desenvolvimento vegetativo dessa cultura até certo ponto, e a partir daí o acréscimo da lâmina de irrigação reduziu os parâmetros vegetativos em estudo.

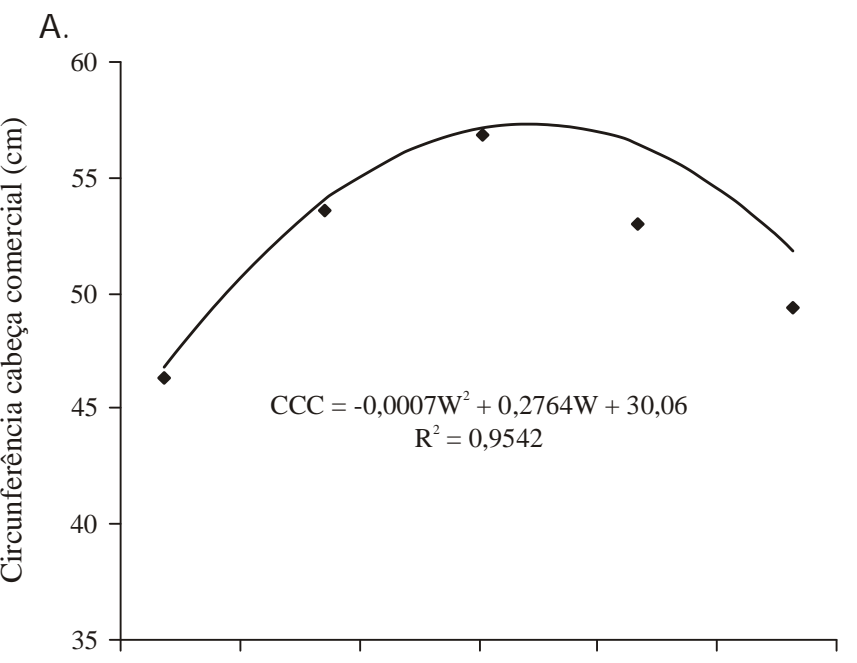

B.

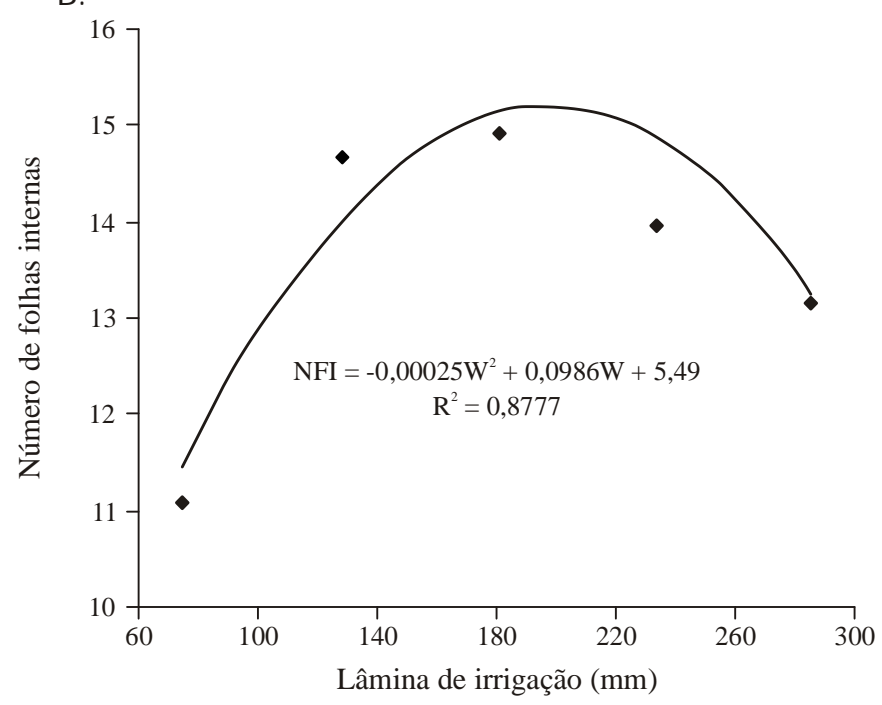

Figura 5. Valores médios, observados e estimados, da circunferência da cabeça comercial (CCC) (A) e do número de folhas internas (NFI) (B), em função de diferentes lâminas de água no solo 
A circunferência da cabeça comercial é uma das principais características da indústria de beneficiamento para se obter rendimentos elevados no processamento; logo, esta característica serve como parâmetro de seleção no momento de aquisição do produto pelos consumidores (Bueno, 1998).

Silva et al. (2008) obtiveram efeito quadrático semelhante para circunferência da cabeça comercial da alface americana, cujo valor máximo de circunferência foi de 44,94 cm, com uma lâmina total de água de 170,81 mm, correspondente a $91,66 \%$ da lâmina de reposição. Porém, este resultado está abaixo do encontrado neste experimento, sendo esta provável diferença ocasionada por épocas de semeaduras diferentes.

Santos \& Pereira (2004), estudando o efeito de diferentes tensões de água no solo sobre o comportamento produtivo da alface americana, cv. Raider, em ambiente protegido, encontraram o máximo de 22,25 folhas internas por planta para a tensão de $15 \mathrm{kPa}$ com uma lâmina de água aplicada de $152,7 \mathrm{~mm}$, sendo este valor de lâmina superior ao encontrado neste trabalho. $\mathrm{O}$ valor máximo verificado neste estudo está abaixo do encontrado no trabalho citado. Deve-se levar em conta, ainda, que os experimentos foram realizados em condições diferentes e, principalmente, em épocas de cultivos também diferentes.

Mota et al. (2001) comentam que, se a cabeça da alface americana estiver compacta, o aumento no número das folhas internas será uma característica desejável para a indústria, pois favorecerá o tamanho da cabeça comercial e o aumento de sua massa. Nas feiras e supermercados tal característica também é interessante, já que confere maior peso à cabeça e facilita a aquisição, pelo consumidor que adquire por unidade e não por peso.

Pelo resultado da análise de variância (Tabela 3), a eficiência no uso da água foi influenciada significativamente pelas lâminas de irrigação aplicadas, pelo teste $\mathrm{F}$ a $1 \%$ de probabilidade.

De acordo com a Figura 6, a eficiência no uso da água apresentou efeito linear decrescente com as lâminas de irrigação aplicadas a $1 \%$ de significância. À medida que os ní-

Tabela 3. Resumo das análises de variância e de regressão para a eficiência no uso da água (EUA), em função de diferentes lâminas de irrigação

\begin{tabular}{lcc}
\hline \multirow{2}{*}{ Fonte de Variação } & G. L. & Q. M. \\
\cline { 3 - 3 } Lâmina & 4 & EUA \\
Bloco & 3 & $88955,40^{* *}$ \\
Resíduo & 12 & $2863,78^{\text {ns }}$ \\
Média $\left(\mathrm{kg} \mathrm{ha}^{-1} \mathrm{~mm}^{-1}\right)$ & - & 5516,65 \\
C.V. $(\%)$ & - & 373,55 \\
Linear & 1 & 19,88 \\
Quadrática & 1 & $352042,17^{* *}$ \\
Desvios & 2 & $1991,43^{\text {ns }}$ \\
\hline
\end{tabular}

ns - não significativo pelo teste $\mathrm{F}$

** - significativo a $1 \%$ de probabilidade pelo teste $F$

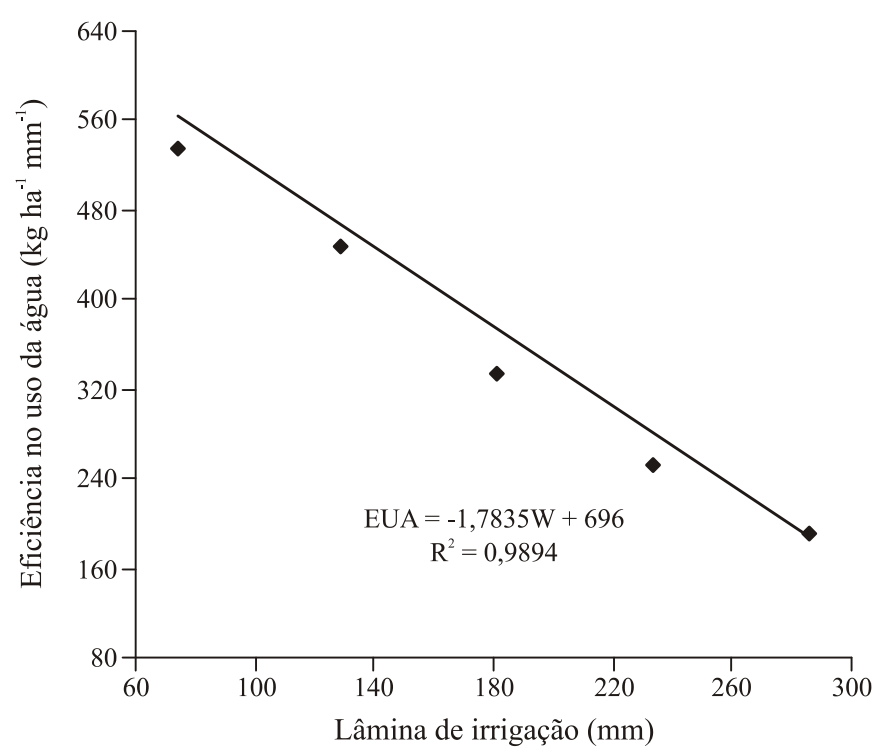

Figura 6. Valores médios, observados e estimados, da eficiência no uso da água (EUA), em função das lâminas de irrigação

veis de irrigação aumentaram, ocorreu diminuição na eficiência no uso da água. Ainda se pode observar que 98,94\% das variações ocorridas na eficiência no uso da água em função das lâminas de irrigação aplicadas, são explicadas pela regressão linear.

O mesmo comportamento foi verificado na cultura da alface, por Vilas Boas et al. (2007) e Andrade Júnior \& Klar (1997), quando da utilização de lâminas maiores, a eficiência tende a decrescer até seu ponto mínimo, atingido seu máximo com lâminas menores.

Sá et al. (2005), trabalhando com tensões de água no solo em ambiente protegido, cultivado com tomate, observaram que a EUA apresentou resposta linear crescente, com o aumento dos valores de tensão.

Os valores de eficiência no uso da água variaram de 563,07 a $186,51 \mathrm{~kg} \mathrm{ha}^{-1} \mathrm{~mm}^{-1}$, com as lâminas de irrigação de 74,53 e 285,65 mm, respectivamente. Obteve-se, ainda, para a lâmina de $181,02 \mathrm{~mm}$, correspondente a $90 \%$ da lâmina de reposição, um rendimento de $373,15 \mathrm{~kg} \mathrm{ha}^{-1} \mathrm{~mm}^{-1}$, esta última considerada ponto médio dentro do intervalo válido para essas observações.

\section{CONCLUSÕES}

1. A máxima produtividade comercial, $35.308 \mathrm{~kg} \mathrm{ha}^{-1}$, foi obtida com a aplicação da lâmina de 204,3 mm, correspondente ao fator de reposição de $101 \%$.

2. As variáveis número de folhas internas e circunferência da cabeça comercial tiveram valores máximos alcançados entre o intervalo de 95 a $110 \%$ de reposição da lâmina evaporada.

3. A maior eficiência no uso da água $\left(563,07 \mathrm{~kg} \mathrm{ha}^{-1} \mathrm{~mm}^{-1}\right)$ ocorreu com a aplicação da lâmina de irrigação de $74,53 \mathrm{~mm}$, correspondente ao fator de reposição de água, de $30 \%$. 


\section{AGRADECIMENTOS}

À Coordenação de Aperfeiçoamento de Pessoal de Nível Superior (CAPES), pela concessão da Bolsa de Auxílio, ao Conselho Nacional de Desenvolvimento Científico e Tecnológico (CNPq), pela concessão das Bolsas de Produtividade e de Iniciação Científica, e ao Departamento de Engenharia da UFLA.

\section{LITERATURA CITADA}

Agrianual - Anuário da agricultura brasileira. Alface. São Paulo: FNP, 2008. p.345.

Andrade Júnior, A. S. de; Klar, A. E. Manejo da irrigação da cultura da alface (Lactuca sativa L.) através do tanque classe A. Scientia Agricola, v.54, n.1/2, p.31-38, 1997.

Bueno, C. R. Adubação nitrogenada em cobertura via fertirrigação por gotejamento para a alface americana em ambiente protegido. Lavras: UFLA, 1998. 54p. Dissertação Mestrado

Dantas, A. A. A.; Carvalho, L. G.; Ferreira, E. Classificação e tendência climática em Lavras, MG. Ciência e Agrotecnologia, v.31, n.6, p.1862-1866, 2007.

EMBRAPA - Empresa Brasileira de Pesquisa Agropecuária. Centro Nacional de Pesquisa de Solos. Sistema brasileiro de classificação de solos. Rio de Janeiro: Embrapa Solos, 1999. 412p.

Filgueira, F. A. R. Novo manual de olericultura: agrotecnologia moderna na produção e comercialização de hortaliças. 2.ed. Viçosa: UFV, 2003. 412p.

Gomes, L. A. A.; Silva, E. C. da; Faquin, V. Recomendações de adubação para cultivos em ambiente protegido. In: Ribeiro, A. C.; Guimarães, P. T. G.; Alvarez V., V. H. (ed.). Recomendações para o uso de corretivos e fertilizantes em Minas Gerais: $5^{\mathrm{a}}$ aproximação. Viçosa: UFV, 1999. p.99-110.

Koetz, M.; Coelho, G.; Costa, C. C. C.; Lima, E. P.; Souza, R. J. Efeito de doses de potássio e da frequiência de irrigação na produção da alface-americana em ambiente protegido. Engenharia Agrícola, v.26, n.3, p.730-737, 2006.

Mota, J. H.; Souza, R. J. S.; Silva, E. C.; Carvalho, J. G.; Yuri, J. E. Efeito do cloreto de potássio via fertirrigação na produção de alface-americana em cultivo protegido. Ciência e Agrotecnologia, v.25, n.3, p.542-549, 2001.

Oliveira, A. C. B.; Sediyama, M. A. N.; Pedrosa, M. W.; Garcia, N. C. P.; Garcia, S. L. R. Divergência genética e descarte de variáveis em alface cultivada sob sistema hidropônico. Acta Scientiarum, v.26, n.2, p.211-217, 2004.
Pelúzio, J. B. E. Crescimento da alface (Lactuca sativa L.) em casa-de-vegetação com seis níveis de água e cobertura do solo com seis filmes coloridos de polietileno. Viçosa: UFV, 1992. 102p. Dissertação Mestrado

Rodrigues, A. B.; Martins, M. I. E. G.; Araújo, J. C. C. Avaliação econômica da produção de alface em estufa. Informações Econômicas, v.27, n.1, p.27-33, 1997.

Sá, N. S. A.; Pereira, G. M.; Alvarenga, M. A. R.; Mattioli, W.; Carvalho, J. A. Comportamento da cultura do tomateiro sob diferentes tensões de água no solo em ambiente protegido. Revista Brasileira de Engenharia Agrícola e Ambiental, v.9, n.3, p.341-347, 2005.

Santana, C. V. S.; Almeida, A. C.; Turco, S. H. N. Produção de alface roxa em ambientes sombreados na região do Submédio São Francisco - BA. Revista Verde de Agroecologia e Desenvolvimento Sustentável, v.4, n.3, p.1-6, 2009.

Santos, S. R.; Pereira, G. M. Comportamento da alface tipo americana sob diferentes tensões de água no solo, em ambiente protegido. Engenharia Agrícola, Jaboticabal, v.24, n.3, p.569-577, 2004.

Segovia, J. F. O.; Andriolo, J. L.; Buriol, G. A.; Schneider, F. M. Comparação do crescimento e desenvolvimento da alface (Lactuca sativa L.) no interior e exterior de uma estufa de polietileno em Santa Maria, RS. Ciência Rural, v.27, n.1, p.37-41, 1997.

Silva, P. A. M.; Pereira, G. M.; Reis, R. P.; Lima, L. A.; Taveira, J. H. S. Função de resposta da alface americana aos níveis de água e adubação nitrogenada. Ciência e Agrotecnologia, v.32, n.4, p.1266-1271, 2008.

Vilas Boas, R. C.; Carvalho, J. A.; Gomes, L. A. A.; Souza, K. J.; Rodrigues, R. C.; Sousa, A. M. G. Efeito da irrigação no desenvolvimento da alface crespa, em ambiente protegido, em Lavras, MG. Revista Brasileira de Engenharia Agrícola e Ambiental, v.11, n.4, p.393-397, 2007.

Volpe, C. A.; Churata-Masca, M. G. C. Manejo da irrigação em hortaliças: método do tanque Classe A. Jaboticabal: FUNEP, 1988. 19p.

Yuri, J. E.; Mota, J. H.; Resende, G. M.; Souza, R. J. de; Rodrigues Júnior, J. C. Desempenho de cultivares de alface tipo americana em cultivo de outono no Sul de Minas Gerais. Ciência e Agrotecnologia, v.28, n.2, p.282-286, 2004.

Yuri, J. E.; Souza, R. J. de; Freitas, S. A. C. de; Rodrigues Júnior, J. C.; Mota, J. H. Comportamento de cultivares de alface tipo americana em Boa Esperança. Horticultura Brasileira, v.20, n.2, p.229-232, 2002. 